\title{
FIBER OPTIC MONITORING OF ACTIVE FAULTS AT THE SEAFLOOR: the FOCUS project
}

Marc-André GUTSCHER ${ }^{1}$, Jean-Yves ROYER ${ }^{1}$, David GRAINDORGE ${ }^{1}$, Shane MURPHY ${ }^{2}$, Frauke KLINGELHOEFER ${ }^{2}$, Chastity AIKEN ${ }^{2}$, Antonio CATTANEO ${ }^{2}$, Giovanni BARRECA ${ }^{3}$, Lionel QUETEL ${ }^{4}$, Giorgio RICCOBENE ${ }^{5}$, Florian PETERSEN ${ }^{6}$, Morelia URLAUB ${ }^{6}$, Sebastian KRASTEL ${ }^{7}$, Felix GROSS ${ }^{7}$, Heidrun KOPP ${ }^{6}$, Lucia MARGHERITI ${ }^{8}$, Laura BERANZOLI

${ }^{1}$ Laboratoire Géosciences Océan, Univ. Brest / CNRS, Plouzané, France, ${ }^{2}$ Géosciences Marines, Ifremer Centre de Bretagne, Plouzané, France, ${ }^{3}$ Dept. of Biological, Geological and Environment Sciences, University of Catania, Catania, Italy, ${ }^{4}$ IDIL Fiber Optics, Lannion, France, ${ }^{5}$ INFN-LNS, Catania, Italy, ${ }^{6}$ GEOMAR Helmholtz Research Centre, Kiel, Germany, ${ }^{7}$ Institute of Geosciences, Kiel University, Kiel, Germany, ${ }^{8}$ INGV, Rome, Italy gutscher@univ-brest.fr

Laser reflectometry (BOTDR), commonly used for structural health monitoring (bridges, dams, etc.), will for the first time be applied to study movements of an active fault on the seafloor $25 \mathrm{~km}$ offshore Catania Sicily. The goal of the European funded FOCUS project (ERC Advanced Grant) is to connect a 6-km long strain cable to the EMSO seafloor observatory in $2100 \mathrm{~m}$ water depth. Laser observations will be calibrated by seafloor geodetic instruments and seismological stations. A long-term goal is the development of dual-use telecom cables with industry partners.
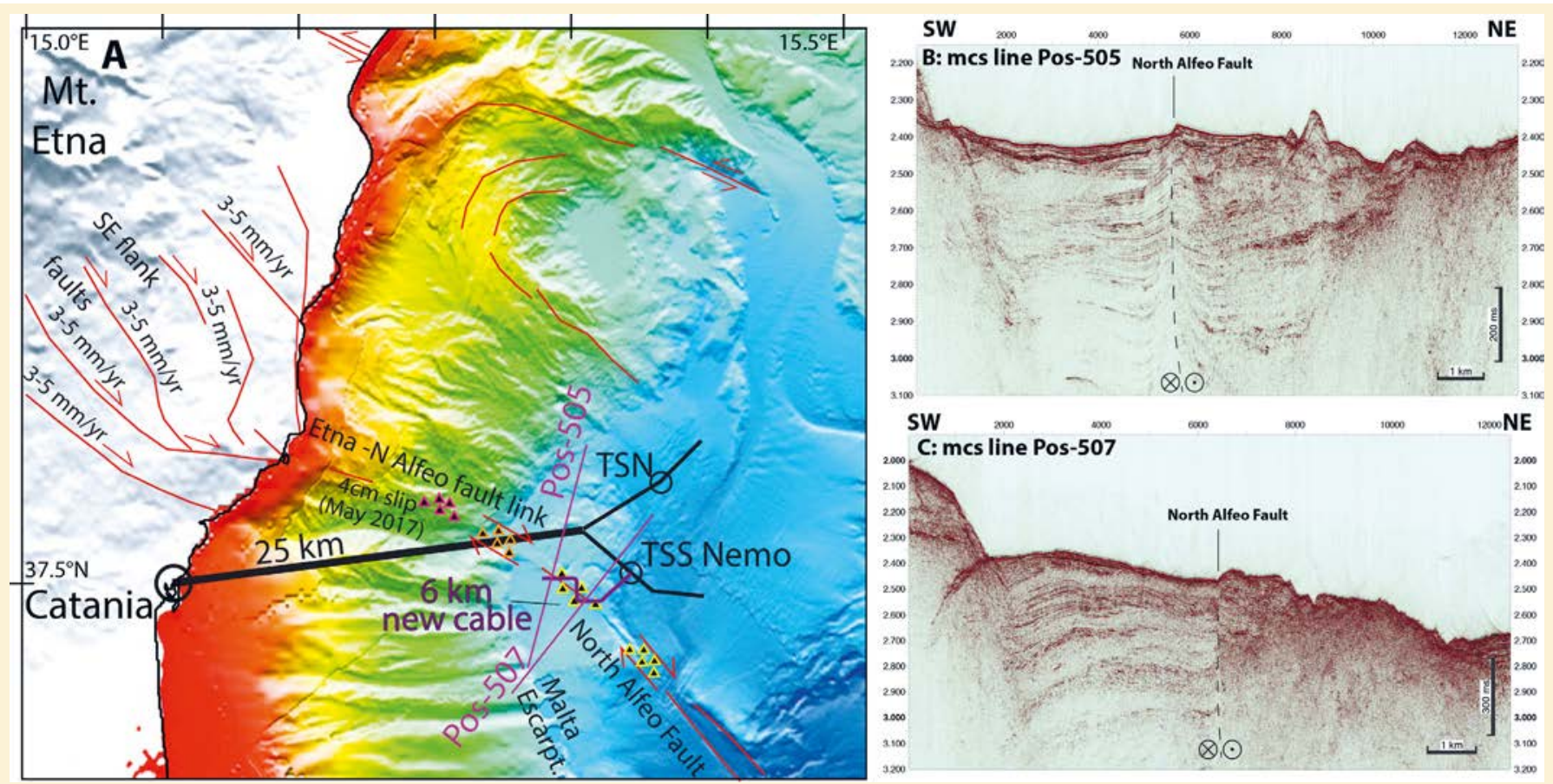

Figure 1. (A) Map of North Alfeo Fault (shown in red), the EMSO Catania cabled seafloor observatory (black lines) and the planned deployment of a 6-km long dedicated strain cable (shown in purple). (B, C) Multi-channel seismic reflection profiles crossing the North Alfeo fault and which show a sharp break in the continuity of reflectors (sedimentary strata) caused by the deformation along the nearly vertical strike-slip fault (for location see Fig. 1A). 
I wo-thirds of the earth's surface is covered by water and thus largely inaccessible to modern networks of seismological instruments. The global network of submarine telecommunication cables, if properly adapted, offers tremendous possibilities as a large-scale seismological monitoring tool for the future. It was recently demonstrated that fiber optic telecommunication cables both on-land and at sea can detect earthquakes [1,2]. Application of laser reflectometry in fiber optic cables can potentially be used to detect movement across active submarine faults in near real time. This is the objective of the ERC (European Research Council) funded project FOCUS (Fiber Optic Cable Use for seafloor studies of earthquake hazard and deformation). BOTDR (Brillouin Optical Time Domain Reflectometry) is commonly used for structural health monitoring of large-scale engineering structures (e.g. bridges, dams, pipelines, etc.) and can measure very small strains $(<<1 \mathrm{~mm} / \mathrm{m})$ at very large distances $(10-200 \mathrm{~km})$. However, this technique has never been used to study faults and deformation on the seafloor.

During the 5-year FOCUS project we aim, using a variety of different instruments, to detect small $(1-2 \mathrm{~cm})$ displacements across the recently mapped North Alfeo Fault, about $20 \mathrm{~km}$ offshore Catania, an urban area of 1 million people. Here, the Catania EMSO (European Multidisciplinary water-column and Seafloor Observatory) station is located in $2100 \mathrm{~m}$ depth and connected to land by a $25 \mathrm{~km}$ long electro-optical cable (Fig. 1). The laser reflectometry observations will be calibrated by seafloor geodetic stations and earthquake activity will be monitored simultaneously by seafloor and onland seismometers. This cable, which crosses the Alfeo Fault, will be the focal point of the FOCUS project.

\section{Instruments formonitoring} fault activity on the seafloor

\section{Fiber optic cables and monitoring technology}

Laser reflectometry techniques permit the use of fiber optic cables to measure fluctuations in temperature and in strain. These techniques are widely used for structural health monitoring of large-scale infrastructure (bridges, hydro-electric dams, tunnels, cooling towers of nuclear power plants, wind turbines, pipelines, skyscrapers, train tracks, etc.) (Fig. 2A). There have also been some studies regarding specific geo-hazards on land, for instance monitoring slow creep of a landslide [3] or collapse of roadways over karst (sinkholes in limestone) [4]. One of the earliest pilot studies in a marine environment tried measuring seafloor displacement across an incipient submarine landslide offshore Santa Barbara California using a strain sensor cable, but proved "unsuccessful in several attempts" due to "broken fiber cable" during deployment [5]. Thus, to this day, there are no documented examples regarding the use of laser reflectometry for monitoring submarine faults.

BOTDR (Brillouin Optical Time Domain Reflectometry), is performed by firing a laser pulse from one end into an optical fiber (Fig. 2B). As laser light diffracts off microscopic imperfections in the fiber it produces several characteristic diffraction peaks (Raleigh, Brillouin, Raman). If the fiber optic cable is disturbed (through strain or temperature variations) then the Brillouin spectrum will vary at this exact location along the fiber (Fig. 2C) compared to a previous measure. Under optimal conditions, deformation on the order of $50 \mu \mathrm{m} / \mathrm{m},(1 / 3 \mathrm{rd}$ the thickness of a human hair), can be easily measured at distances of several tens of $\mathrm{km}$, and located to within $1 \mathrm{~m}$ [6]. These detection limits are 2 orders of magnitude better than typical land-based GPS techniques. Testing BOTDR in a deep-sea offshore environment is a great technological challenge. It requires vessels, highly specialized equipment and is very expensive. Application of this method could revolutionize the study of submarine faults, plate tectonics and earthquake hazard, while helping to improve early warning capability.
YOUR EXPERT IN

PHOTONIC

INTEGRATION

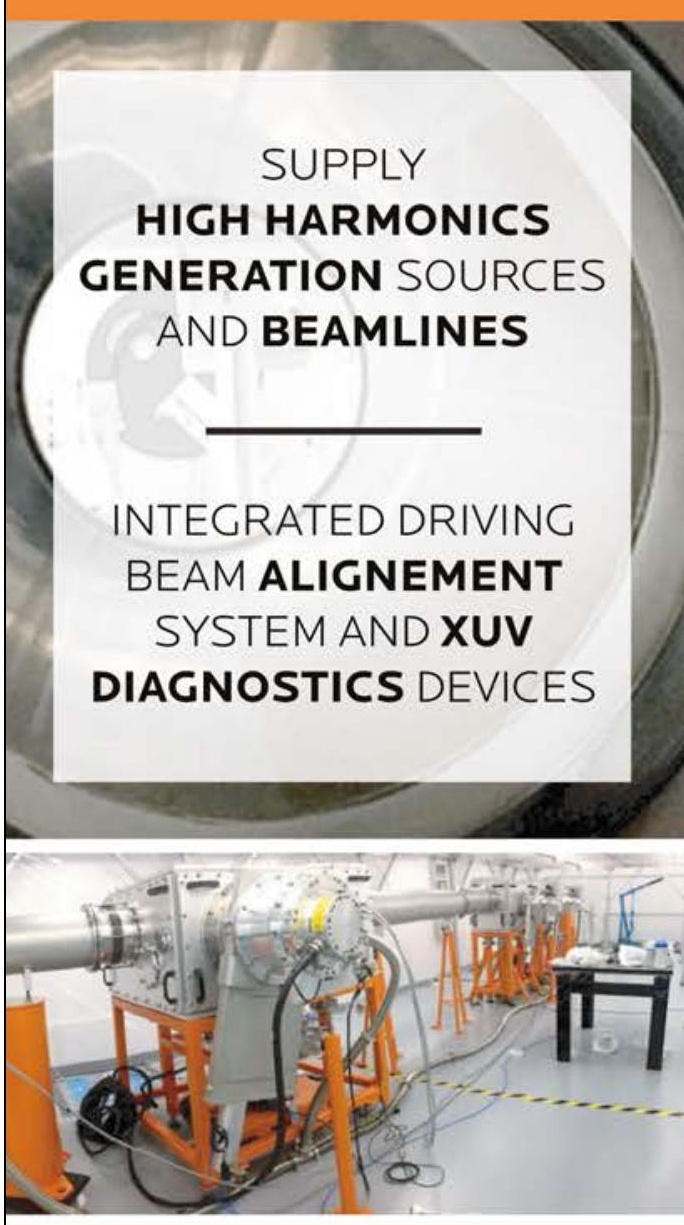

LASER

PHOTOMETRY

RADIOMETRY

COLORIMETRY

SPECTROSCOPY
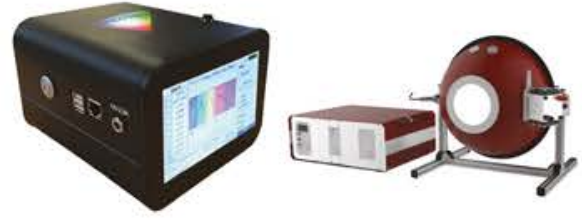

INTEGRATOR

PARTNER

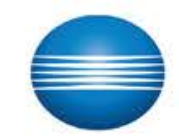

KONICA MINOLTA 

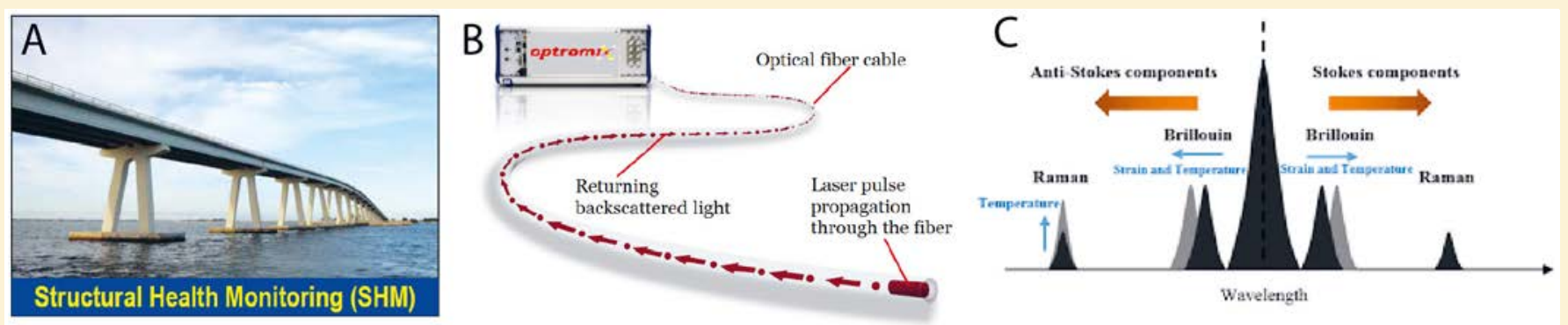

Figure 2. BOTDR (Brillouin Optical Time Domain Reflectometry) (A) Application to monitoring large scale infrastructure. (B) Principle how laser light is diffracted by minute imperfections in the optical fiber. (C) Three diffraction peaks, central peak is the Raleigh peak, the Brillouin peak is sensitive to temperature and strain variations.

A private company, IDIL fiber optics, is a partner of the ERC project FOCUS and has already conducted preliminary experiments on the EMSO cable infrastructure (in the framework of a Brittany Region funded BoostERC project - pre-FOCUS). IDIL will be in charge of the laser reflectometry measurements to be performed over several years on the EMSO Catania cable and the 6-km long extension (dedicated fiber optic strain cable). The Italian Physics Institute (INFN-LNS), operator of the EMSO cable infrastructure in Sicily (Catania and Capo Passero) collaborated for the preliminary experiments. They are also closely involved in the FOCUS project and will provide logistical and operational support during the planned marine expedition in summer 2020 and in particular the operations of cable deployment and cable connection.

\section{Seafloor geodetic instruments}

Seafloor geodetic stations communicate via acoustic signals at regular intervals with each other, while continuously measuring the sound velocity in water, and can therefore measure the length of all the interconnecting baselines continuously (Fig. 3). The stations also have pressure sensors and tiltmeters to ensure that any movement recorded is not simply settling or sliding of a single instrument. This methodology will be applied during the FOCUS project to calibrate the displacement along the target fault. GEOMAR and Laboratoire Géosciences Océan are among the pioneers in Europe in seafloor geodesy and have already worked together using this method in the Marmara Sea [7].

An array of five seafloor geodetic instruments was deployed by Geomar and the Univ. of Kiel along the offshore continuation of strike-slip and normal faults accomodating a gradual eastward gravitational collapse of the southeast flank of Mt. Etna (Fig. 4A) [8]. This network was deployed in water depths of 900-1200 $\mathrm{m}$ and recovered in August 2018. Analysis of baseline length changes during the 20 -month observation period indicates a dextral strike-slip movement of $4 \mathrm{~cm}$ (Fig. 4B) along the fault trace [8], with nearly all the movement having occurred during a slow slip event in May 2017. The cumulative motion of the Etna flank faults (Fig. 4A) is estimated to be about $2-4 \mathrm{~cm} / \mathrm{yr}[8,9]$. The slip observed by the seafloor geodetic network is roughly of the same order and indicates an active submarine fault about $20 \mathrm{~km}$ to the east of Catania, an urban area of 1 million people, and crossed by the EMSO Catania cable (Fig. 2A). The seismic hazard posed by this major fault and its deep offshore continuation, with a total length of $\sim 80 \mathrm{~km}$ [10] and unknown prior to 2010 , has yet to be properly estimated. The FOCUS project can provide a major contribution to this seismic hazard assessment by measuring the spatial variation in coupling (i.e. the degree to which the two sides of the fault are locked/sliding) along the fault and by quantifying current slip rates.

\section{Seismological stations}

During the fiber optic and laser reflectometry observations, a regional passive seismological experiment is planned to record regional seismicity (Fig. 5). A temporary network of OBS (Ocean Bottom Seismometers) will be deployed on the seafloor to record regional earthquakes, which will also be simultaneously recorded by INGV seismic stations on land (Fig. 5) supplemented by deployment of temporary seismic stations on land. The regional seismicity as observed by only land based seismological stations (Fig. 5) is characterized by a concentration of events related to volcanic activity of Mt. Etna (as magma rises through the

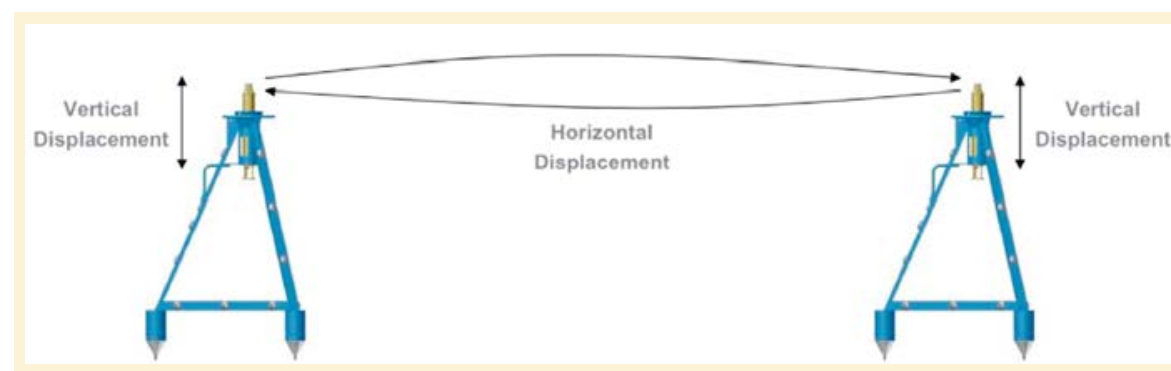

Figure 3. Seafloor geodetic stations, which communicate through acoustic transponders thus measuring the baseline length. Typical baseline lengths are 200-3000 m. 

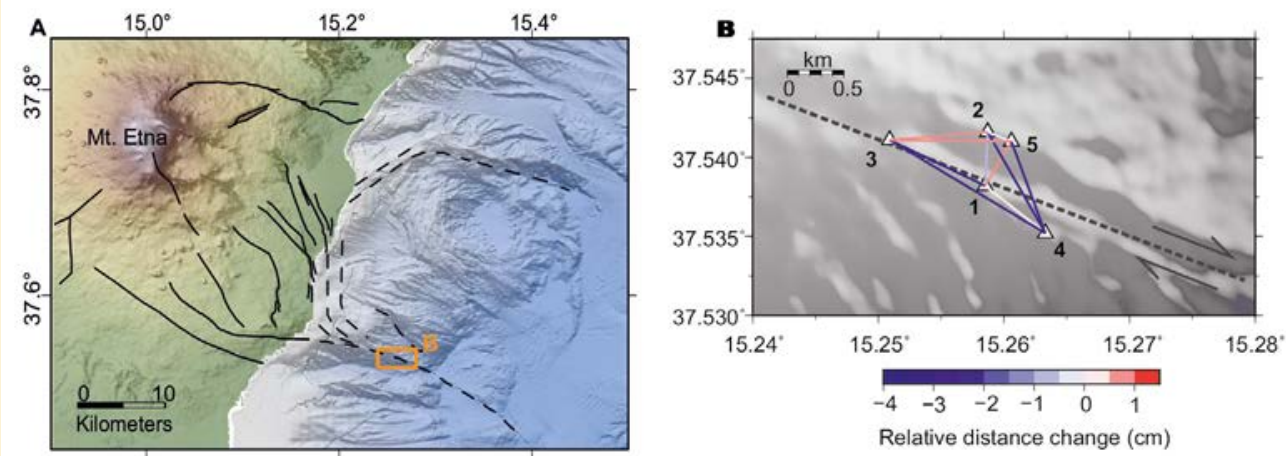

deep conduits and erupts at the surface). There is also a zone with broad diffuse seismicity observed offshore (east of Sicily and south of Calabria) in the Ionian Sea, without any apparent structural pattern (alignment along specific faults). This seismicity is possibly the result of two types of tectonic activity at different depths. In this region there is the gently northwest dipping subduction interface of the Calabria subduction zone, which lies in the depth range of $15-30 \mathrm{~km}$. The other major tectonic structures are the strike-slip faults, well expressed in the morpho-bathymetry [9] and observed in seismic profiles as well (Fig. 1B,C). Given the low magnitudes (2.5-3.5) and absence of nearby seismological stations providing good azimuthal coverage, it is very difficult to locate these earthquakes properly, horizontally and particularly in depth.
Figure 4. (A, left) Regional map showing position (red square) of seafloor geodetic network deployed offshore Catania / Mt. Etna (Apr. 2016 - Aug. 2018) by Geomar and Univ. Kiel [8]. (B, right) Change in base-line lengths over 20-months (Apr. 2016 - July 2017) with $4 \mathrm{~cm}$ of dextral strike-slip movement detected between the NE stations ( 2 and 5 ) and the SW stations ( 3,1 and 4$)$, and interpreted to have occurred during an 8 day slow slip event in May 2017 [8].
Therefore, one of the major goals of the planned marine expedition in 2020 is to deploy a network of 35 ocean bottom seismometers, at a fairly dense spacing in proximity to the EMSO Catania cable and the North Alfeo fault, but also spanning a broader regional zone including the other major strike slip faults and the NW portion of the subducting Ionian slab. Italian partners INGV are ready to cooperate through

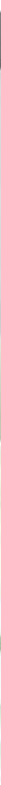

Contact:

Promessa, Tel. +33134571144 promessa@promessa.com
JUNE 24-27, 2019, MESSE MUNCHEN

24th World's Leading Trade Fair with Congress for Photonics Components, Systems and Applications 


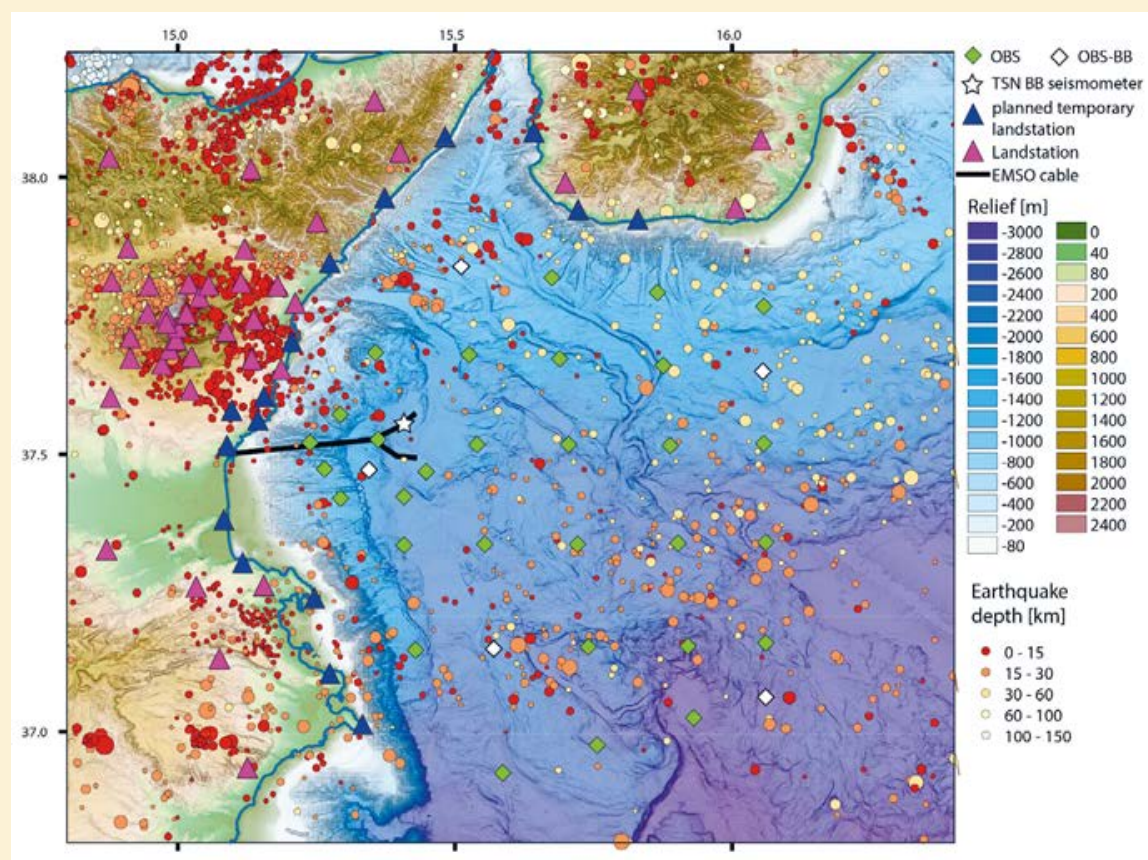

Figure 5. Map of the East Sicily - SW Calabria - Ionian Sea region, showing regional seismicity (colored circles), the existing network of land stations operated by INGV (magenta triangles), the planned temporary network of 30 short-period ocean bottom seismometers (green diamonds), and 5 broad-band OBS (white diamonds). Possible deployment of 16 temporary land-stations is also shown (blue triangles). deployment of instruments on the seafloor offshore Sicily is the availability of ship time. A requested 4-week marine expedition FocusX1 could take place in summer 2020 if approved. Otherwise there may be options for cable deployment through collaboration with Orange (a major telecommunications cable operator). Once the cable, seafloor geodetic stations and ocean-bottom seismometers have been deployed, there will be a 3-4 year period of observation, with $\mathrm{PhD}$ students and young post-doctoral scientists who will contribute together with the permanent staff involved to collect and process the data collected and to calibrate the measurements obtained from the different methods. If all goes according to plan, slow or sudden displacements along the North Alfeo fault will be detected by the BOTDR technique as well as by the seafloor geodetic stations. sharing of the earthquake recordings from their land-based seismological network (magenta black triangles, Fig. 5). There is a high concentration of seismic stations on the summit region of Mt Etna and around most of the slopes. However, the SE slope, and where recently mapped strike-slip faults show displacement rates of a few $\mathrm{mm} / \mathrm{yr}$ (Figs. 1, 4A), is sparsely covered by seismic stations. INGV has agreed to add stations here, in the region directly north and northeast of Catania and on the SE flank of Mt. Etna.

\section{Project status and outlook}

Currently the project is in its earliest stage, having begun on 1 Oct. 2018. Nearly all the necessary equipment has been ordered / purchased. Upon delivery an initial phase of testing will take place, first in the lab, next in the $25 \mathrm{~m}$ deep Ifremer test pool, and then in shallow water in the nearby Bay of Brest (Rade de Brest). The critical factor for beginning the

\section{FURTHER READING}

[1] Marra, G., Clivatti, C., Luckett, R., Tampellini, A., Kronjäger,J., Wright, L., Mura, A., Levi, F., Robinson, S., Xuereb, A., Baptie, B., Calonico, D., Ultrastable laser interferometry for earthquake detection with terrestrial and submarine cables. Science (2018) https://doi.org/10.1126/science.aat4458

[2] Jousset, P., Reinsch, T., Ryberg, T., Blanck, H., Clarke, A., Aghayef, R., Hersir, G.P., Henninges, J., Weber, M., Krawcyk, C.M., Dynamic strain determination using fibre-optic cables allows imaging of seismological and structural features. Nature Communications, 9, 2509 (2018) https://doi. org/10.1038/s41467-018-04860-y

[3] Sun, Y., Shi, B., Zhang, B., Tong, H., Wei, G., Xu, H., Internal deformation monitoring of slope based on BOTDR. J. Sensors (2016) https://doi.org/10.1155/2016/9496285

[4] Jiang, X., Gao, Y., Wu, Y., Lei, M., Use of Brillouin optical time domain reflectometry to monitor soil-cave and sink hole formation. Environ. Earth Sci., 75, 225 (2016) https://doi.org/10.1007/ s12665-015-5084-1

[5] Blum, J.A., Nooner, S.L., Zumberge, M.A., Recording earth strain with optical fibers. IEEE Sensors Journal, 8, 1152-1160 (2008) https://doi.org/10.1109/JSEN.2008.926882

[6] Maraval, D., Gabet, R., Jaouen, Y., Lamour, V., Dynamic optical fiber sensing with Brillouin Optical Time Domain Reflectometry: Application to pipeline vibration monitoring. J. Lightwave Technology (2017) https://doi.org/10.1109/JLT.2016.2614835

[7] Sakic, P., Piete, H., Ballu, V., Royer, J. Y., Kopp, H., Lange, D., Petersen, F., Özeren, M.S., Ergintav, S., Géli, L., Henry, P., Deschamps, A., No significant steady state surfacecreep along the North Anatolian Fault offshore Istanbul: Results of 6 months of seafloor acoustic ranging. Geophysical Research Letters, 43, 6817-6825 (2016)

[8] Urlaub, M., Petersen, F., Gross, F., Bonforte, A., Puglisi, G., Guglielmino, F., Krastel, S., Lange, D., Kopp, H., Gravitational collapse of Mount Etna's south-eastern flank. Science Advances, 4, eeat9700 (2018) https://doi.org/10.1126/sciadv.aat9700

[9] Bonforte, A., Guglielmino, F., Colteli, M., Ferretti, A., Puglisi, G., Structural assessment of Mount Etna volcano from permanent scatterers analysis. Geochemistry, Geophysics, Geosystems, 12, Q02002 (2011) https://doi.org/10.1029/2010GC003213

[10] Gutscher, M.-A., Kopp, H., Krastel, S., Bohrmann, G., Garlan, T., Zaragosi, S., Klaucke, I., Wintersteller, P., Loubrieu, B., LeFaou, Y., San Pedro, L., Dominguez, S., Rovere, M., Mercier de Lepinay, B., Ranero, C., Sallares, V., Active tectonics of the Calabrian subduction revealed by new multi-beam bathymetric data and high-resolution seismic profiles in the Ionian Sea (Central Mediterranean). Earth Planet. Sci. Lett., 461, 61-72 (2017) https://doi.org/10.1016/j.epsl.2016.12.020 


\section{iXblue}

ModBox CS-SSB:

the agile iXblue laser source for cold atoms accelerometers

iXblue is a high-tech enterprise originally founded in 2000 to provide a new class of instruments based on fiber-optic gyroscope technology. They now offer a range of cuttingedge components and instruments that are unsurpassed in terms of sensitivity, precision and stability for applications in navigation, positioning and attitude control. iXblue's verticallyintegrated organization incorporates the development and production of specialty optical fibers, lithiumniobate phase modulators, and quartz accelerometers. In its continuous pursuit of scientific innovation, iXblue has invested in the most advanced technologies for inertial navigationmost recently in the field of coldatom physics, which has emerged as a potential breakthrough technology due to the inherent advantages of atomic spectroscopy and matterwave interferometry. For this reason, iXblue has been collaborating for the past five years with LP2N (Laboratoire Photonique, Numérique, et Nanosciences) at the Institut d'Optique d'Aquitaine (IOA) in Bordeaux. LP2N is today one of the world's leading laboratories in the physics of lasercooled atoms and atomic inertial sensors-a field which has made spectacular progress over the past two decades. The coherent control and manipulation of atomic wavepackets with light can be harnessed to construct extremely sensitive and low-bias inertial sensors-making them interesting candidates to replace classical sensors. However, the use of cold atoms in navigation and positioning applications still faces many scientific and technological challenges.

The joint Laboratory iXAtom was created within the IOA, with a team of researchers, engineers and $\mathrm{PhD}$ students. The aim of this collaboration is to make technological advances using laser-cooled atoms to develop

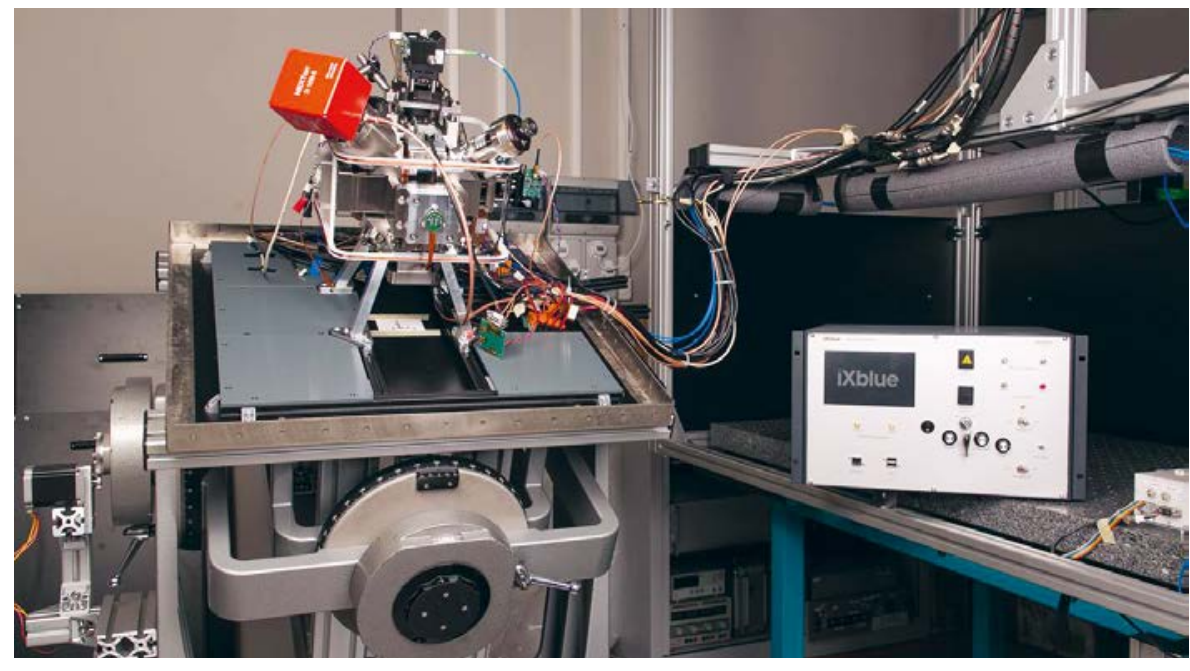

the next generation of inertial sensors for industrial, military and Space applications. In the near future, iXAtom plans to develop a compact three-axis accelerometer based on new techniques in atom interferometry. The ultimate goal of this collaboration is to build an autonomous hybrid device which can compete with technologies based on global positioning systems without the drawback of external communication for recalibration.

Work is being carried out on three major axes: (i) the development of a navigation-compatible cold-atom sensor head, (ii) new theoretical approaches to the operation and enhanced performance of such an instrument, (iii) feasibility experiments carried out to verify the validity of relevant concepts. The laser system is an essential building block of these quantum sensors. Using recent developments in Telecom fiber-based technology, a new laser architecture was developed for laser-cooling and manipulating rubidium atoms. This ModBox laser source, patented in 2018, is based on an iXblue MXIQ-ER CS-SSB optical modulator operating at $1560 \mathrm{~nm}$ and second-harmonic generation to 780 $\mathrm{nm}$. This key component suppresses the carrier frequency by $25 \mathrm{~dB}$ at $1560 \mathrm{~nm}$ and generates two optical sidebands that can be independently controlled in power, frequency and phase using off-the-shelf RF components. These principle sidebands are used to induce allowing one to split, reflect and recombine atomic wavepackets to realize an inertial sensor. With this innovative architecture, the characteristics of the RF source in terms of agility, stability, and response time are directly transferred into the optical signal thanks to electro-optic modulation. The iXAtom team recently realized an atomic accelerometer with this new ModBox laser source, and demonstrated improved performance compared to other laser architectures based on standard phase modulators. Beyond these promising scientific results, the collaboration between iXblue and the LP2N is exemplary of successful transfer of knowledge and technology between a prestigious academic laboratory and high-tech industry.

CONTACT
IXBLUE
Hervé Gouraud, iXblue
herve.gouraud@ixblue.com
Baptiste Battelier, LP2N,
baptiste.battelier@institutoptique.fr
www.ixblue.com
optical transitions in rubidium- 